\title{
A nanobody targeting carcinoembryonic antigen as a promising molecular probe for non-small cell lung cancer
}

\author{
HAO WANG ${ }^{1}$, AI-MIN MENG ${ }^{1}$, SHENG-HUA LI $^{2}$ and XIAO-LIANG ZHOU ${ }^{1}$ \\ ${ }^{1}$ Tianjin Key Laboratory of Radiation Medicine and Molecular Nuclear Medicine, Institute of \\ Radiation Medicine, Chinese Academy of Medical Sciences and Peking Union Medical College, \\ Tianjin 300192; ${ }^{2}$ Tianjin Shengfa NabioTech Co., Ltd., Tianjin 300457, P.R. China
}

Received April 28, 2016; Accepted March 23, 2017

DOI: $10.3892 / \mathrm{mmr} .2017 .6677$

\begin{abstract}
Carcinoembryonic antigen (CEA) is a biomarker and therapy target for non-small cell lung cancer (NSCLC), which is the most common type of lung cancer. Nanobodies with high target specificity are promising candidates to function as anti-CEA probes. In the present study, the targeting effects of an anti-CEA nanobody obtained from phage display were investigated using technetium-99 m $\left({ }^{99 \mathrm{~m}} \mathrm{Tc}\right)$ and fluorescence labeling. In vitro binding and immunofluorescent staining assays, as well as in vivo blood clearance and biodistribution assays were performed. High specificity and affinity of the nanobody for CEA-positive H460 cells was observed in vitro. The pharmacokinetics assay of the ${ }^{99 \mathrm{~m}} \mathrm{Tc}$-nanobody in Wistar rats demonstrated that the nanobody had appropriate $\mathrm{T}_{1 / 2} \alpha$ and $\mathrm{T}_{1 / 2} \beta$, which were 20.2 and $143.5 \mathrm{~min}$, respectively. The biodistribution assay using H460 xenograft-bearing nude mice demonstrated a high ratio of signal in tumor compared with background, which confirmed that the nanobody may be useful as a molecular probe for CEA-positive cancer, particularly in NSCLC.
\end{abstract}

\section{Introduction}

Carcinoembryonic antigen (CEA) is a glycoprotein, which was first identified from human colon adenocarcinoma and the fetal digestive system $(1,2)$. CEA is overexpressed on the cell surface of a variety of carcinomas (3). CEA overexpression is observed in patients with a variety of carcinomas, including in the colon, thyroid, lung, uterus, pancreas and ovary, and the serum levels of CEA are increased in certain cancer types.

Correspondence to: Dr Xiao-Liang Zhou, Tianjin Key Laboratory of Radiation Medicine and Molecular Nuclear Medicine, Institute of Radiation Medicine, Chinese Academy of Medical Sciences and Peking Union Medical College, 238 Baidi Road, Nankai, Tianjin 300192, P.R. China

E-mail: zhouxiaoliang@irm-cams.ac.cn

Key words: nanobody, carcinoembryonic antigen, targeting, fluorescence, radiolabeling
CEA can be used as a cancer marker in clinical testing; it can also be used as a prognostic marker for cancer after radiotherapy and chemotherapy $(4,5)$, a predictive factor for cancer treatment (6), and as a therapeutic target $(7,8)$. Radiolabeled monoclonal antibodies (mAbs) have been developed for the treatment and diagnosis of CEA-positive cancers (9). Nevertheless, the pharmacokinetics of intact mAbs that exhibit slow blood elimination and high liver uptake of are not ideal for their use as cancer-targeted probes $(10,11)$. Smaller antibody fragments, such as antigen-binding fragment (Fab) and single chain fragment variable, particularly nanobodies, have better pharmacokinetics for use as cancer-targeted probes due to their rapid metabolism and high uptake by tumors. The nanobodies with a prolate shape of $\sim 4.2 \mathrm{~nm}$ in length and $2.5 \mathrm{~nm}$ in diameter (12) are the smallest intact antigen-binding fragments $(15 \mathrm{kDa})$ available, which were first isolated from heavy-chain camelid antibodies, and have efficient and specific cancer targeting ability $(11,13)$. Nanobodies have several advantages, including high stability, ease of manufacturing with high yield, fast elimination and high affinity to the target site; thus, they may be suitable as cancer imaging probes and therapeutic vectors.

The incidence of cancer has sustained an increase in the last decades, and lung cancer occupies a large proportion of cancer case. It was estimated that lung and bronchus cancer accounted for $13.3 \%$ of all new cancer cases in 2016, and the percent survival in 2006-2012 was $17.7 \%$ in America (14). The major type of lung cancer is non-small cell lung cancer (NSCLC), which accounts for up to $85 \%$ of all types of lung cancer. Serum CEA level is useful as a prognostic and predictive marker for overall survival, and risk of recurrence and death in lung cancer, particularly in NSCLC, regardless of the treatment received $(15,16)$. Combined with other indicators for lung cancer, CEA can be a diagnostic marker $(17,18)$ and useful target for NSCLC therapy (19).

The present study investigated the targeting of a nanobody (code: $15.2 \mathrm{~m}$ ) to CEA, with fluorescein isothiocyanate (FITC)-labeled immunofluorescent staining, radiotechnetium-labeled cell binding and biodistribution assays on the H460 CEA-positive human large cell lung cancer cell line. The results indicated that the nanobody targets CEA-positive cells; therefore, it may serve as a promising targeted probe for NSCLC. 


\section{Materials and methods}

Chemicals. The nanobody (code, 15.2m; molecular weight, $15 \mathrm{kDa}$ ) was obtained from a phage display library as described previously $(20,21)$. Fresh technetium-99 m ( ${ }^{99 \mathrm{~m} T c)}$ pertechnetate eluant was purchased from the China Institute of Atomic Energy (Beijing, China). Sodium borohydride, $\mathrm{HCl}$, sodium potassium tartrate tetrahydrate, sodium carbonate, and fluorescent dyes (FITC and DAPI) were purchased from Sigma-Aldrich (Sigma-Aldrich; Merck KGaA, Darmstadt, Germany). Silica gel plates were obtained from Yantai Jiangyou Silica Gel Development Co., Ltd. (Yantai, China). Carbon monoxide and carbon dioxide were purchased from Tianjin KUNTENG Gas Marketing Co. Ltd. (Tianjin, China). Ultracentrifugal filter units with a molecular weight cut-off of 3,000 Da were purchased from EMD Millipore (Billerica, MA, USA) and used as per the manufacturer's manual. RPMI-1640 medium, penicillin, fetal bovine serum (FBS), and streptomycin were purchased from Hyclone (GE Healthcare Life Sciences, Logan, UT, USA). Human serum was obtained from the Tianjin Blood Center (Tianjin, China). All procedures using human sera were approved by and conducted in accordance with the regulations of the Ethics Committee of the Institute of Radiation Medicine, Chinese Academy of Medical Sciences (Tianjin, China).

Cell culture and animals. H460 cells were obtained from the Cell Resource Center of the Institute of Basic Medical Sciences of the Chinese Academy of Medical Sciences/Peking Union Medical College (Beijing, China) and cultured in RPMI-1640 medium supplemented with 10\% FBS, $100 \mathrm{U} / \mathrm{ml}$ penicillin, and $100 \mu \mathrm{g} / \mathrm{ml}$ streptomycin at $37^{\circ} \mathrm{C}$ and $5 \% \mathrm{CO}_{2}$. Female BALB/c nude mice (age, 4-5 weeks; weight, 18-20 g) and female Wistar rats (age, 6-8 weeks; weight, 200-250 g) were purchased from the Experimental Animal Center of Academy of Military Medical Sciences (Beijing, China). All animals were kept under controlled temperature $\left(20-22^{\circ} \mathrm{C}\right)$ and $12 \mathrm{~h}$ light/dark cycles with ad libitum access to food and water. All animal procedures were approved by and conducted in accordance with the regulations of the Ethics Committee of the Institute of Radiation Medicine, Chinese Academy of Medical Sciences (Tianjin, China).

Immunofluorescent staining assay. The nanobody (1 mg) was diluted three times against PBS; subsequently, $600 \mu \mathrm{l}$ FITC ( $1 \mathrm{mg} / \mathrm{ml}$ in DMSO) was added, and the mixture was gently stirred for $24 \mathrm{~h}$ at $4^{\circ} \mathrm{C}$. The reaction mixture was purified by ultrafiltration, and washed twice to remove the unreacted dyes. The FITC-nanobody was obtained, and the absorbance at 280 and $495 \mathrm{~nm}$ was measured to determine the concentration of the nanobody and the ratio of FITC to the nanobody. Following washing twice with PBS, the H460 cells seeded in 24-well plates at a density of $4 \times 10^{4}$ cells/well were fixed with ethanol for $10 \mathrm{~min}$ at room temperature; then $0.5 \mathrm{ml}$ serum-free medium and $100 \mu \mathrm{l}$ FITC-nanobody solution (concentration was adjusted according to the absorbance) were added sequentially. Following incubation for $80 \mathrm{~min}$ at $4^{\circ} \mathrm{C}$, the fluorescent images were acquired using a fluorescence microscope (DMI6000B; Leica Microsystems, Inc., Buffalo Grove, IL, USA), and the nuclei were stained using DAPI.
Radioactive technetium labeling. The nanobody was labeled with ${ }^{99 \mathrm{~m}} \mathrm{Tc}$ at its His6 tail, as described previously $(22,23)$. Briefly, $1 \mathrm{ml}$ of the fresh ${ }^{99 \mathrm{~m}} \mathrm{Tc}$-pertechnetate eluant $(10 \mathrm{mCi})$ was added to a mixture of $4 \mathrm{mg}$ sodium carbonate, $22 \mathrm{mg}$ sodium borohydride and $15 \mathrm{mg}$ sodium potassium tartrate tetrahydrate. The mixture was reacted in a boiling water bath for $20 \mathrm{~min}$ under atmospheric carbon monoxide to obtained the $\left[{ }^{99 \mathrm{~m}} \mathrm{Tc}\left(\mathrm{H}_{2} \mathrm{O}\right)_{3}(\mathrm{CO})_{3}\right]^{+}$. After adjusting to a neutral $\mathrm{pH}$ using $1 \mathrm{~mol} / 1 \mathrm{HCl}$, the $\left[{ }^{99 \mathrm{~m}} \mathrm{Tc}\left(\mathrm{H}_{2} \mathrm{O}\right)_{3}(\mathrm{CO})_{3}\right]^{+}$was added to a nanobody solution $(1 \mathrm{mg} / \mathrm{ml})$ and incubated for $90 \mathrm{~min}$ at $50^{\circ} \mathrm{C}$.

Purification and radiochemical purity test. The ${ }^{99 \mathrm{~m}} \mathrm{Tc}-\mathrm{nano}-$ body solution was purified by ultrafiltration and washed twice using PBS to remove the dissociative $\left[{ }^{99 m} \mathrm{Tc}\left(\mathrm{H}_{2} \mathrm{O}\right)_{3}(\mathrm{CO})_{3}\right]^{+}$. Then the ${ }^{99 \mathrm{~m}} \mathrm{Tc}-$ nanobody solution was passed through a $0.22-\mu \mathrm{m}$ Millipore filter (EMD Millipore) to eliminate possible aggregates. Thin layer chromatography (TLC) was then performed to determine the labeling efficiency and radiochemical purity of the ${ }^{99 \mathrm{~m}} \mathrm{Tc}$-nanobody, directly after labeling and after purification. The analytes were spotted on silica gel plates, which were subsequently developed in acetone and detected using an AR-2000 radio-TLC Imaging Scanner equipped with a $10 \%$ methane:argon gas supply and the running analysis software Winscan version v.3 (Bioscan Inc., Washington, DC, USA). The analysis of crude mixtures was used to calculate the yield, and the analysis of the purified product was used to calculate the radiochemical purity.

In vitro stability. Two portions of $100 \mu 1^{99 \mathrm{~m}} \mathrm{Tc}-$ nanobody were added to $500 \mu \mathrm{l}$ normal saline at room temperature and $500 \mu \mathrm{l}$ human serum at $37^{\circ} \mathrm{C}$, respectively. Radiochemical purities were determined using thin layer chromatography as mentioned above at 1, 2, 6 and $24 \mathrm{~h}$.

In vitro evaluation of the ${ }^{99 m}$ Tc-nanobody. $\mathrm{H} 460$ cells were seeded in 24-well plates, at a density of $4 \times 10^{4}$ cells/well. Following overnight incubation, the cells were washed twice using cold PBS then the ${ }^{99 \mathrm{~m}} \mathrm{Tc}$-nanobody was added at concentrations of 0.02 to $80 \mathrm{nM}$. The plates were incubated on ice for $1 \mathrm{~h}$ then washed using cold PBS two times. Portions of $1 \mathrm{ml}$ sodium hydroxide $(1 \mathrm{~mol} / \mathrm{l})$ were added and the plates were incubated at room temperature for $1 \mathrm{~h}$. The lysates were collected and the radioactivity was measured by a $\gamma$ counter (2470 WIZARD2; PerkinElmer, Inc., Waltham, MA, USA). The blocking experiment was performed by adding $50 \mu \mathrm{g}$ cold nanobody to the wells and incubating each for $30 \mathrm{~min}$ before adding the ${ }^{99 \mathrm{~m}} \mathrm{Tc}-$ nanobody.

Blood clearance of the ${ }^{99 m}$ Tc-nanobody. Wistar rats $(\mathrm{n}=3)$ were injected with $10 \mu \mathrm{Ci}{ }^{99 m} \mathrm{Tc}-$ nanobody via the cauda vein. Blood samples were collected using microcapillaries at 1, 5, $10,20,40,60,90$, and $120 \mathrm{~min}$ after the injection, and the radioactivity was measured using a $\gamma$ counter to obtain a radioactivity-time curve. Data are presented as the percentage injected activity per total blood weight (\% ID/g). Total blood weight was calculated as $7 \%$ of the total body weight.

Biodistribution. The distribution of the ${ }^{99 \mathrm{~m}} \mathrm{Tc}$-nanobody was investigated using nude mice bearing subcutaneously-implanted 

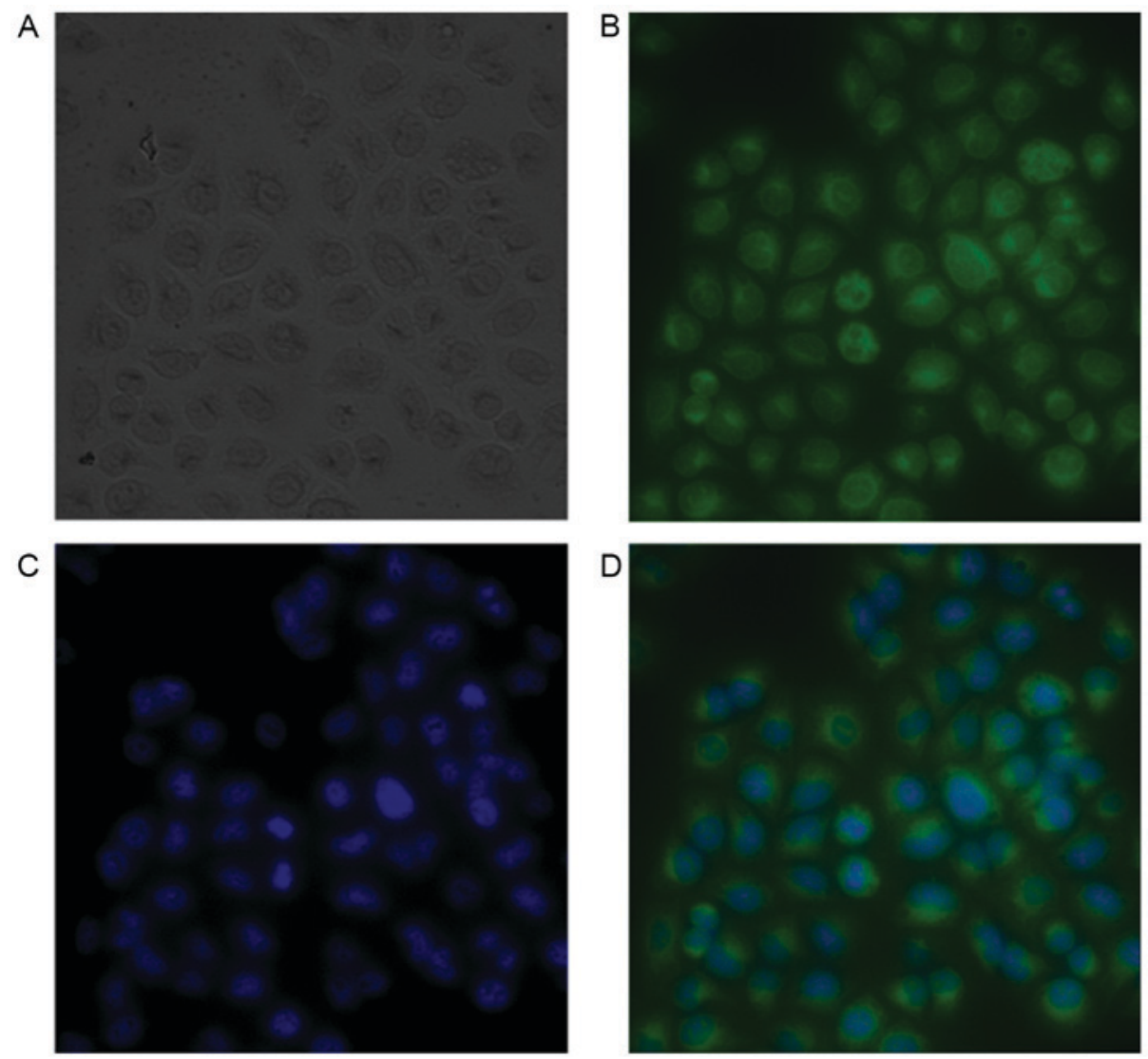

Figure 1. Images of FITC-nanobody stained H460 cells observed under x40 magnification. (A) Light microscopy, (B) FITC fluorescence, (C) DAPI fluorescence, and (D) overlay FITC and DAPI. Immunofluorescence demonstrated that the nanobody adhered to the surface of CEA-positive H460 cells. FITC, fluorescein isothiocyanate.

human xenografts of $\mathrm{H} 460$ cells. The $\mathrm{H} 460$ cells $\left(1 \times 10^{7}\right)$ in $200 \mu 1$ PBS were subcutaneously injected into the left armpit of female BALB/c nude mice $(n=4)$ to establish the xenograft tumors. After the tumor volume reached approximately $200 \mathrm{~mm}^{3}$, the mice were injected with $100 \mu \mathrm{Ci}{ }^{99 m} \mathrm{Tc}-n a n o-$ body via the tail vein. At 1,2, and $6 \mathrm{~h}$ post-injection, four mice were anesthetized, exsanguinated and dissected. Blood, tumor and normal tissues were weighed, and radioactivity was measured using a $\gamma$ counter. Radioactivity uptake was calculated as $\% \mathrm{ID} / \mathrm{g}$.

Statistical analysis. The statistical significance of the differences between groups was assessed using two-tailed Student's t-test. Data are expressed as the mean \pm standard deviation of three independent experiments. $\mathrm{P}<0.05$ was considered to indicate a statistically significant difference. Statistical analysis was performed using the GraphPad Prism software version 5 (GraphPad Software, Inc., La Jolla, CA, USA).

\section{Results}

Immunofluorescent staining. The concentration of nanobody and the ratio of FITC to nanobody were determined by [(A280-0.31xA495)/1.4] and [3.1xA495/(A280-0.31xA495)] respectively and the results were $0.254 \mathrm{mg} / \mathrm{ml}$ and 10.1 ; the FITC-nanobody was diluted twice using PBS for staining test. The fluorescent images are presented in Fig. 1.
Purification and radiochemical purity. The ${ }^{99 \mathrm{~m}} \mathrm{Tc}-$ nanobody and the dissociative $\left[{ }^{99 \mathrm{~m}} \mathrm{Tc}(\mathrm{H} 2 \mathrm{O}) 3(\mathrm{CO}) 3\right]+$ were separated well on silica gel plates using acetone as the developing solvent. The radiolabeling efficiency, which was determined using thin layer chromatography, was $87.0 \%$ (Fig. 2A). The crude product was then purified by ultrafiltration to obtain the ${ }^{99 \mathrm{~m}} \mathrm{Tc}$-nanobody, of which radiochemical purity was $97.1 \%$ (Fig. 2B).

In vitro stability. The radiochemical purity of the ${ }^{99 \mathrm{~m}} \mathrm{Tc}-$ nanobody was assessed in normal saline at $25^{\circ} \mathrm{C}$ and in human serum at $37^{\circ} \mathrm{C}$. Under both conditions, the ${ }^{99 \mathrm{~m}} \mathrm{Tc}-$ nanobody exhibited good stability (Fig. 3).

In vitro evaluation of the ${ }^{99 m}$ Tc-nanobody. An in vitro binding assay was performed using CEA-positive H460 cells, the ${ }^{99}$ Tc-nanobody exhibited a normal binding manner that was effectively blocked by cold nanobody (Fig. 4).

Blood clearance of the ${ }^{99 m} T c$-nanobody. As per the radioactivity-time curve presented in Fig. 5, the blood elimination was fast during the initial $50 \mathrm{~min}$ and it then slowed. The half-lives of distribution $\left(\mathrm{T}_{1 / 2} \alpha\right)$ and elimination $\left(\mathrm{T}_{1 / 2} \beta\right)$ were 20.2 and 143.5 min, respectively (Fig. 5).

Biodistribution. Nude mice bearing H460 xenografts were injected with the ${ }^{99 \mathrm{~m}} \mathrm{Tc}$-nanobody and sacrificed at 1,2 and $6 \mathrm{~h}$. The radioactivity of different tissues was measured with a $\gamma$ counter. The result demonstrated that the radiolabeled 
A

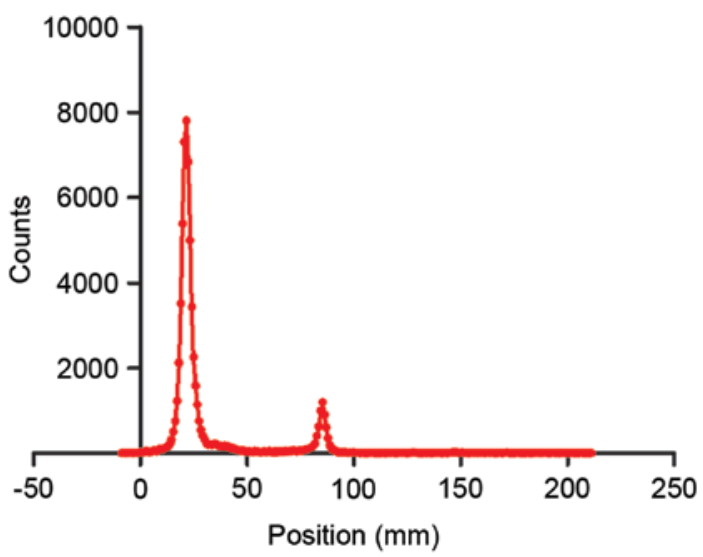

B

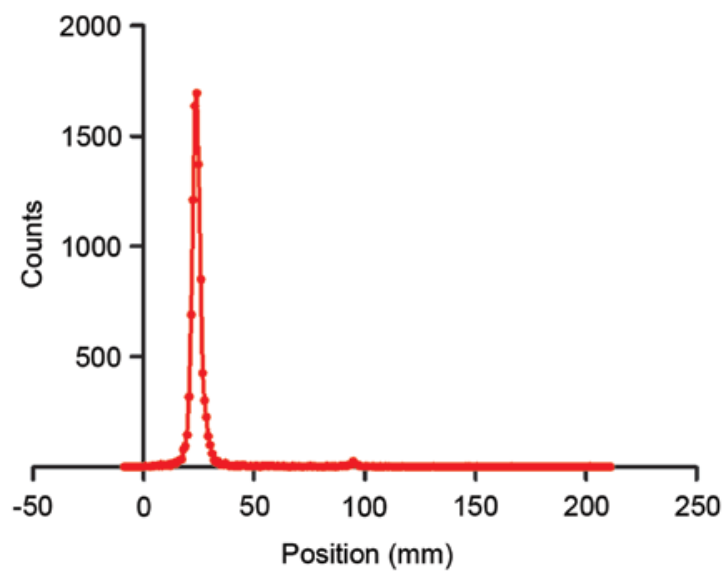

Figure 2. Labeling efficiency and radiochemical purity. The labeling efficiency and radiochemical purity were assayed using silica gel plates. The ${ }^{99 \mathrm{~m}} \mathrm{Tc}$-nanobody had an RF of 0.11 , and the RF of $\left[{ }^{99 \mathrm{~m}} \mathrm{Tc}\left(\mathrm{H}_{2} \mathrm{O}\right)_{3}(\mathrm{CO})_{3}\right]^{+}$was 0.47. (A) Labeling efficiency was $87.0 \%$. (B) Following purification, the radiochemical purity of the ${ }^{99 \mathrm{~m}} \mathrm{Tc}-$ nanobody was $97.1 \%$. RF, retention factor; ${ }^{99 \mathrm{~m}} \mathrm{Tc}$, technetium-99 m.

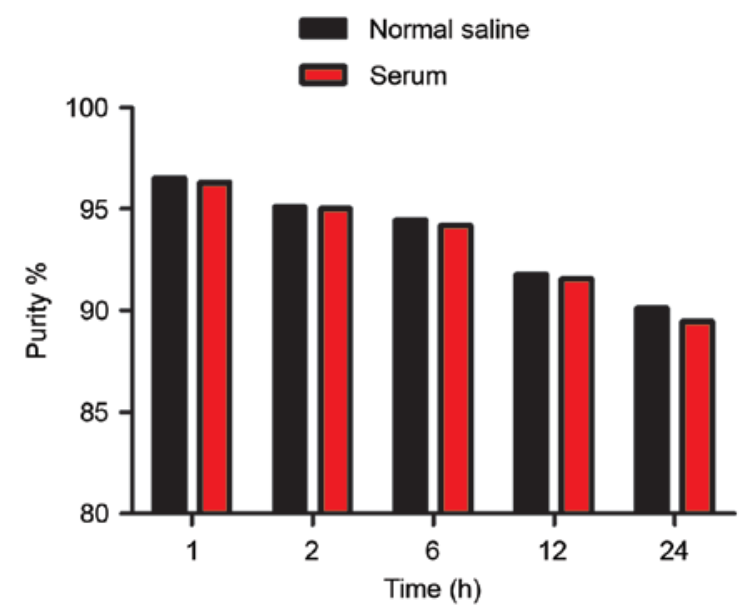

Figure 3. In vitro stability. Radiochemical purity of the ${ }^{99 \mathrm{~m}} \mathrm{Tc}-$ nanobody remained $>90.1 \%$ and $89.5 \%$ periodically over $24 \mathrm{~h}$ in normal saline at room temperature $\left(25^{\circ} \mathrm{C}\right)$ and in human serum at $37^{\circ} \mathrm{C}$, respectively. ${ }^{99 \mathrm{~m}} \mathrm{Tc}$, technetium-99 m.

nanobody was predominantly excreted through the kidney, and partially accumulated in the liver and spleen. A high uptake by tumor was observed. The high uptake by bone may

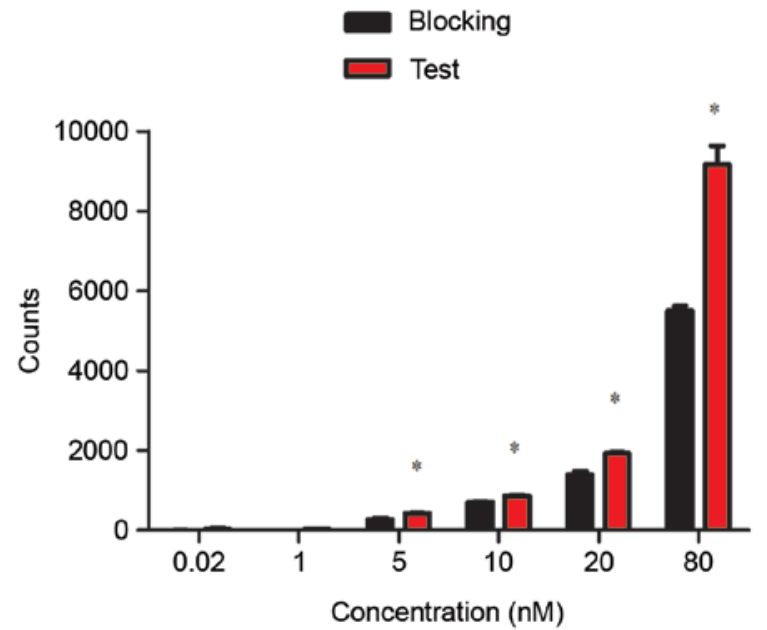

Figure 4. Specific binding of the ${ }^{99 \mathrm{~m}} \mathrm{Tc}$-nanobody. The ${ }^{99 \mathrm{~m}} \mathrm{Tc}$-nanobody was incubated with $\mathrm{H} 460$ cells at a concentration of 0.02 to $80 \mathrm{nM}$, which exhibited a normal binding manner (red); when the cells were pretreated with cold nanobody, the binding was blocked (black). Data were analyzed using two-tailed t-test, ${ }^{\mathrm{P}}<0.05$ vs. blocking. ${ }^{99 \mathrm{~m}} \mathrm{Tc}$, technetium- $99 \mathrm{~m}$.

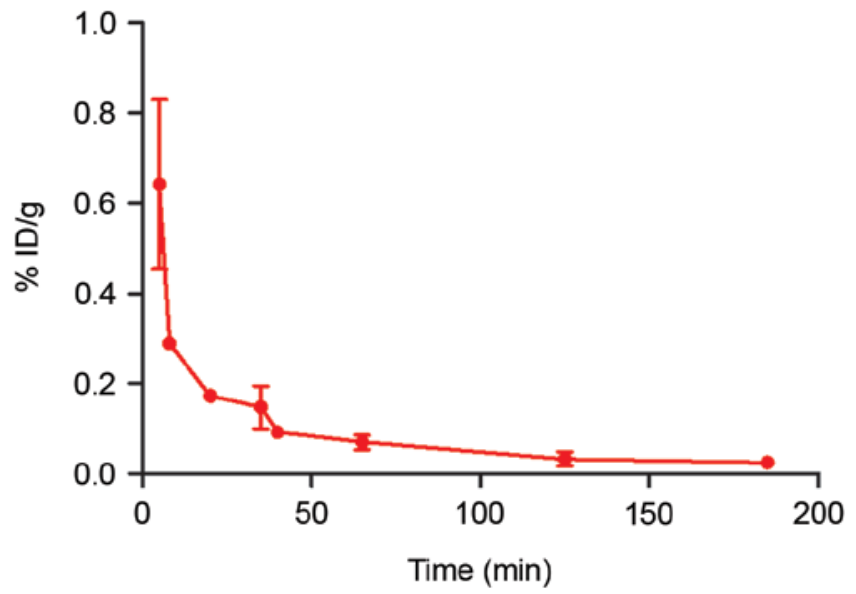

Figure 5. Blood clearance of the ${ }^{99 \mathrm{~m}} \mathrm{Tc}-$-nanobody. Wistar rats $(\mathrm{n}=3)$ were injected with the ${ }^{99 \mathrm{~m}} \mathrm{Tc}$-nanobody. Blood was drawn at different time-points, and radioactivity was measured with a $\gamma$ counter to obtained the radioactivity-time curve; data are presented as $\% \mathrm{ID} / \mathrm{g} . \mathrm{T}_{1 / 2} \alpha$ and $\mathrm{T}_{1 / 2} \beta$ were 20.2 and $143.5 \mathrm{~min}$, respectively. ${ }^{99 \mathrm{~m}} \mathrm{Tc}$, technetium- $99 \mathrm{~m}$.

be caused by the dissociation of the radionuclide from the ${ }^{99 \mathrm{~m}}$ Tc-nanobody in vivo (Fig. 6).

\section{Discussion}

Molecular imaging has become an all-important tool in cancer diagnosis and targeted therapy; it involves the use of probes coupled to molecules with appropriate signal-emitting tags $(11,24,25)$. Nanobodies are suitable for molecular imaging as they have several advantages, including fast distribution and elimination, high affinity and specificity, ease of manufacturing, and high stability. This study evaluated the targeting profile of a nanobody against CEA with the objective of developing a new probe for the molecular imaging of NSCLC. On account of appropriate decay characteristics and the ease of labeling with a His-tag that is far from the activity site of the probe, ${ }^{99 \mathrm{~m}} \mathrm{Tc}$ is the most commonly used signal tag in 


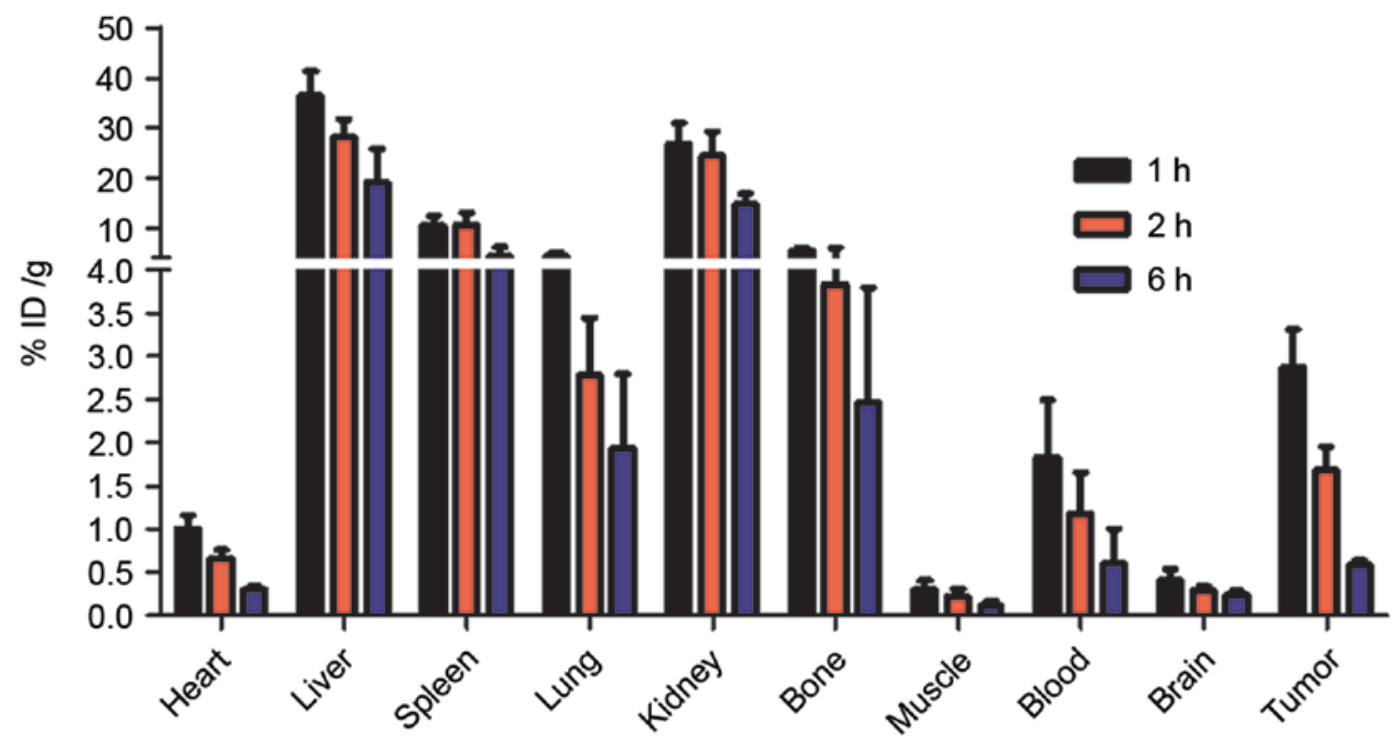

Figure 6. Biodistribution of the ${ }^{99 \mathrm{~m}} \mathrm{Tc}-$ nanobody in xenograft-bearing nude mice. Data are presented as $\% \mathrm{ID} / \mathrm{g}$ and expressed as the mean \pm standard deviation $(n=4)$. High uptake by tumor was observed as early as $1 \mathrm{~h}$ after injection, the ratio of tumor-to-muscle exceeded 10, and the ratio of tumor-to-blood reached 1.8, and higher uptake of kidneys caused by the renal clearance. The high uptake in normal tissues was caused due to dissociation of ${ }^{99} \mathrm{mTc}$ from the ${ }^{99} \mathrm{mTc}$-nanobody. Higher uptake in tumor tissue compared with in blood and muscle tissue supports its use as a molecular probe. ${ }^{99 \mathrm{~m}} \mathrm{Tc}$, technetium-99 $\mathrm{m}$.

nanobody imaging experiments (11). Therefore, ${ }^{99 \mathrm{~m}} \mathrm{Tc}-$ labeling was used to investigate the distribution and elimination of CEA-targeting nanobody with the aim to develop a clinically relevant single photon emission computed tomography probe.

In the present study, in vitro immunofluorescent staining indicated efficient binding of the nanobody to CEA-positive cells. The ${ }^{99 \mathrm{~m}} \mathrm{Tc}-$ nanobody exhibited good stability in normal saline and serum. The binding and blocking experiment revealed that the ${ }^{99 \mathrm{~m}} \mathrm{Tc}-$ nanobody had normal and specific affinity for CEA-positive cells. The $\mathrm{T}_{1 / 2} \alpha$ and $\mathrm{T}_{1 / 2} \beta$ were 20.2 and $143.5 \mathrm{~min}$, respectively. The radioactivity-time curve revealed suitable pharmacokinetics for its use in imaging. Biodistribution data in nude mice with H460 xenografts revealed rapid tumor uptake and specific tumor targeting by the ${ }^{99 \mathrm{~m}}$ Tc-nanobody. A high tumor-to-background ratio further confirmed its use in CEA-positive cancers. The radioactivity in tumor tissue was nine times higher than the background of the muscle, indicating a favorable distribution for imaging; a high uptake in the kidney indicated its urinary excretion. All these results present the nanobody as a potentially useful molecular probe for NSCLC.

In conclusion, a pilot study was conducted using a CEA-targeted nanobody to investigate its NSCLC targeting effects. In vitro binding, in vivo distribution and pharmacokinetics assays were performed, and the results indicate that the nanobody may be a promising molecular probe for CEA-positive tumors, particularly in NSCLC cases.

\section{Acknowledgements}

The authors would like to thank Dr Jian-Feng Liu (Institute of Radiation Medicine, Chinese Academy of Medical Sciences and Peking Union Medical College, Tianjin, China) for his suggestion in experiment design. Useful technical assistance was provided by Professor Jian Tan (Tianjin Medical University General Hospital, Tianjin, China). This study was funded by the National Natural Science Foundation of China (grant nos. 1301983 and 81502759), The IRM-CAMS Research Fund (grant no. 1529) and Natural Science Foundation of Tianjin (grant no. 15JCQNJC45800).

\section{References}

1. Gold P and Freedman SO: Demonstration of tumor-specific antigens in human colonic carcinomata by immunological tolerance and absorption techniques. J Exp Med 121: 439-462, 1965.

2. Krupey J, Gold P and Freedman SO: Purification and characterization of carcinoembryonic antigens of the human digestive system. Nature 215: 67-68, 1967.

3. Wahl RL, Philpott G and Parker CW: Monoclonal antibody radioimmunodetection of human-derived colon cancer. Invest Radiol 18: 58-62, 1983.

4. Jeon BG, Shin R, Chung JK, Jung IM and Heo SC: Individualized cutoff value of the preoperative carcinoembryonic antigen level is necessary for optimal use as a prognostic marker. Ann Coloproctol 29: 106-114, 2013.

5. Yang KL, Yang SH, Liang WY, Kuo YJ, Lin JK, Lin TC, Chen WS, Jiang JK, Wang HS, Chang SC, et al: Carcinoembryonic antigen (CEA) level, CEA ratio, and treatment outcome of rectal cancer patients receiving pre-operative chemoradiation and surgery. Radiat Oncol 8: 43, 2013.

6. Eftekhar E and Naghibalhossaini F: Carcinoembryonic antigen expression level as a predictive factor for response to 5 -fluorouracil in colorectal cancer. Mol Biol Rep 41: 459-466, 2014.

7. Das A, Barik S, Banerjee S, Bose A, Sarkar K, Biswas J, Baral R and Pal S: A monoclonal antibody against neem leaf glycoprotein recognizes carcinoembryonic antigen (CEA) and restricts CEA expressing tumor growth. J Immunother 37: 394-406, 2014

8. Conaghan P, Ashraf S, Tytherleigh M, Wilding J, Tchilian E, Bicknell D, Mortensen NJ and Bodmer W: Targeted killing of colorectal cancer cell lines by a humanised IgG1 monoclonal antibody that binds to membrane-bound carcinoembryonic antigen. Br J Cancer 98: 1217-1225, 2008.

9. Koppe MJ, Bleichrodt RP, Soede AC, Verhofstad AA, Goldenberg DM, Oyen WJ and Boerman OC: Biodistribution and therapeutic efficacy of (125/131)I-, (186)Re-, (88/90)Y-, or (177) Lu-labeled monoclonal antibody $\mathrm{MN}-14$ to carcinoembryonic antigen in mice with small peritoneal metastases of colorectal origin. J Nucl Med 45: 1224-1232, 2004.

10. Olafsen $\mathrm{T}$ and $\mathrm{Wu}$ AM: Antibody vectors for imaging. Semin Nucl Med 40: 167-181, 2010. 
11. Chakravarty R, Goel S and Cai W: Nanobody: The 'magic bullet' for molecular imaging? Theranostics 4: 386-398, 2014.

12. Siontorou CG: Nanobodies as novel agents for disease diagnosis and therapy. Int J Nanomedicine 8: 4215-4227, 2013.

13. Desmyter A, Decanniere K, Muyldermans S and Wyns L: Antigen specificity and high affinity binding provided by one single loop of a camel single-domain antibody. J Biol Chem 276 26285-26290, 2001

14. Cancer of the Lung and Bronchus-SEER Stat Fact Sheets 2016: 2016.

15. Grunnet M and Sorensen JB: Carcinoembryonic antigen (CEA) as tumor marker in lung cancer. Lung Cancer 76: 138-143, 2012.

16. Tomita M, Shimizu T, Ayabe T, Yonei A and Onitsuka T: Prognostic significance of tumour marker index based on preoperative CEA and CYFRA 21-1 in non-small cell lung cancer. Anticancer Res 30: 3099-3102, 2010.

17. Ghosh I, Bhattacharjee D, Das AK, Chakrabarti G, Dasgupta A and Dey SK: Diagnostic role of tumour markers CEA, CA15-3, CA19-9 and CA125 in lung cancer. Indian J Clin Biochem 28: 24-29, 2013.

18. Dai H, Liu J, Liang L, Ban C, Jiang J, Liu Y, Ye Q and Wang C: Increased lung cancer risk in patients with interstitial lung disease and elevated CEA and CA125 serum tumour markers. Respirology 19: 707-713, 2014

19. Liu GL, Liu X, Lv XB, Wang XP, Fang XS and Sang Y: miR-148b functions as a tumor suppressor in non-small cell lung cancer by targeting carcinoembryonic antigen (CEA). Int J Clin Exp Med 7: 1990-1999, 2014.
20. Bell A, Wang ZJ, Arbabi-Ghahroudi M, Chang TA, Durocher Y, Trojahn U, Baardsnes J, Jaramillo ML, Li S, Baral TN, et al: Differential tumor-targeting abilities of three single-domain antibody formats. Cancer Lett 289: 81-90, 2010 .

21. Wu W, Li S, Zhang W, Sun J, Ren G and Dong Q: A novel VHH antibody targeting the B cell-activating factor for B-cell lymphoma. Int J Mol Sci 15: 9481-9496, 2014.

22. Xavier C, Devoogdt N, Hernot S, Vaneycken I, D'Huyvetter M, De Vos J, Massa S, Lahoutte T and Caveliers V: Site-specific labeling of his-tagged Nanobodies with ${ }^{99} \mathrm{mTc}$ : A practical guide. Methods Mol Biol 911: 485-490, 2012.

23. Gainkam LO, Huang L, Caveliers V, Keyaerts M, Hernot S, Vaneycken I, Vanhove C, Revets H, De Baetselier P and Lahoutte T: Comparison of the biodistribution and tumor targeting of two $99 \mathrm{mTc}-$ labeled anti-EGFR nanobodies in mice, using pinhole SPECT/micro-CT. J Nucl Med 49: 788-795, 2008.

24. Aerts A, Impens NR, Gijs M, D'Huyvetter M, Vanmarcke H, Ponsard B, Lahoutte T, Luxen A and Baatout S: Biological carrier molecules of radiopharmaceuticals for molecular cancer imaging and targeted cancer therapy. Curr Pharm Des 20: 5218-5244, 2014

25. Teng FF, Meng X, Sun XD and Yu JM: New strategy for monitoring targeted therapy: Molecular imaging. Int J Nanomedicine 8: 3703-3713, 2013 